\title{
Pollen-based predictive modelling of wine production: application to an arid region
}

Mário Cunha $^{\mathrm{a}, b^{*}}$, Helena Ribeiro ${ }^{\mathrm{a}, \mathrm{c}}$ and Ilda Abreu ${ }^{\mathrm{a}, \mathrm{c}}$

a. Faculdade de Ciências, Universidade do Porto, Rua do Campo Alegre, s/n, 4169-007 Porto, Portugal.

b. Centro de Investigação em Ciências Geoespaciais, Rua do Campo Alegre, s/n, 4169-007 Porto, Portugal.

c. Instituto de Ciências da Terra (ICT), Pólo da Faculdade de Ciências da Universidade do Porto, Rua Campo Alegre, 4169-007 Porto, Portugal.

*Corresponding author: mcunha@mail.icav.up.pt

Abstract

A wine forecast model for one of the most arid wine regions of the Europe - Alentejo was improved and tested for the period 1998 to 2014. During this period, Alentejo region had strong upward trends in wine production associated to the increase of vineyard area. The forecast model was supported on a hierarchical analysis, including the determination of the potential production at flowering by quantifying airborne pollen concentration, followed by a climate based evaluation of the possible impact of fruit-set conditions in the limitation of production. Through the monitoring of airborne pollen flows it is possible to define an accurate main pollen season and determine the regional pollen index that will be used as independent variable in the regional forecast model. The time trend, which was initially removed from data, was then added back to obtain the forecast. Stepwise regression and cross-validation were employed during the period 1998 to 2014 for calibration of the model used for predicting annual wine production. The developed model explained about $86 \%$ of wine variance over the years with absolute average error of $6 \%$ for the cross validation and $87 \%$ of cases had differences between actual and forecasted wine production below 10\%. The reliability and earlyindication ability of the proposed forecast model justify their use to respond to a number of government agencies and wine industry concerns and activities.

Key words: grapevine, wine industry, crop yield forecast, airborne pollen, fruit-set

\section{Introduction}

Grapevines are one of the main worldwide perennial crops, with more than seven million ha of grapevines grown along all continents except Antarctica. Grapevines grow from temperate to tropical regions, ranging from $50^{\circ} \mathrm{N}$ to $43^{\circ} \mathrm{S}$, with the most concentrated vineyards occurring in Europe. Portugal is number five in the European wine producers' ranking and number eleven worldwide (OIV, 2015).

In Portugal, as in many other countries, the last decades were characterized by large inter-annual variation of wine production with adverse effects for all the contributors involved in wine industry. Unpredictable variations in wine production are a major threat to the governmental agencies and wine industry (e.g. Clingeleffer et al., 2001). Therefore, there is a strong demand for improved wine yield forecasting in order to improve the efficiency of vineyard and winery operations as well as to support commercial strategies. It is essential for efficient harvest organization (machinery and staff) and to support thinning practices to improve the grape 
quality (Sabbatini and Howell, 2012). Yield forecasts also help vintners to estimate cooperage and equipment demands for crush as well as to evaluate grape supplies, organize delivery schedules, support regional pricing negotiations and the development of marketing strategies (Clingeleffer et al., 2001; de la Fuente et al., 2015). The Governments and European Commission's policy makers can use forecast information to implement regulator mechanisms provided under the Common Organization of Wine Market for moderating the interannual wine variability effects (e.g. price policy, assign economic aid, crop insurance contracts, production quotas, and stock management (Cunha et al., 2010; Quiroga and Iglesias, 2009).

An example is the AGRI4CAST system, managed by the Monitoring Agriculture with Remote Sensing (MARS) that is actually devoted to monitor and forecast yields for annual key European crops (AGRI4CAST, 2015; Vossen and Rijks, 1995). However, there is still a great lack of knowledge concerning the yield forecasting for perennial crops, particularly in predicting wine production.

Grapevine yield components based methods are the basis of most popular approaches for grapevine yield forecasting (Clingeleffer et al., 2001; de la Fuente et al., 2015; Huglin and Schneider, 1998; Panigai and Moncomble, 1988; Sabbatini and Howell, 2012). Such approach requires the manual inspection in trial plots of the number of clusters per vine and the number of berries per cluster, generally sampling at fruit-set period or veraison. This value is typically, multiplied by an estimate of cluster weight at harvest to predict yield per vine. The number of vines in the area of interest is then used to estimate grapevine yield per hectare. The accuracy of this approach is greatly dependent on the quality of cluster sampling, which is generally limited by labour requirements and costs especially when large areas are concerned (Dunn, 2010).

Grapevine yield forecasts can also be carried out with field-scale crop simulation models which apply detailed crop physiology, growth and development traits and requirements (Bindi et al., 1996; Cola et al., 2014; ValdesGomez et al., 2009). However, the grapevine perennial nature and its permanent structures (roots and wooden stem), which provide carbon and nutrients reserves, are highly influenced by past years agroclimatic conditions variability (Guilpart et al., 2014; May, 2004). Therefore, the developing of grapevine simulation models is a highly complex task as many of the important carry-over effects on growth or cropping are still not fully understood and are difficult to be inputted as model variables (Vasconcelos et al., 2009).

Because the complexity and data requirements of simulation models for grapevine, many previous studies have favoured the use of empirical regression methods based upon on climate data (called agrometeorological models) to forecast wine production (e.g. Cunha and Richter, 2012; Lobell et al., 2007; Santos et al., 2013). Such approach has been criticized for the use of no sound predictors and for not to providing the scientific understanding of the biophysical process under study.

In the past few years, a number of grapevine yield forecast models has been developed based on several techniques such as image processing for detecting and classifying grape and berries in vineyards (Nuske et al., 2014), indirect real-time method for grapevine yield forecast based on with trellis tension monitors (Blom and 
Tarara, 2009) or even regional wine production model based on satellites images requirements (Cunha et al., 2010). However, the practical improvement of using these approaches as well as its operational and commercially application for wine industry have not yet been establisched.

In perennial crops such as grapevine, the existence of a relationship between the amount of airborne pollen and the size of the harvest has been shown (Cour and Van Camp, 1980). This approach was also applied in crop yield forecast at regional level for different perennial crops besides the grapevine such as olive in Portugal, Spain, Italy, Morocco and Tunisia (Abid, 1991; Oteros et al., 2014; Ribeiro et al., 2009), apple in France (Pinchon, 1983), citrus in Morocco (Abid, 1991) and hazelnut in Spain (Lltejos et al., 1993). This crop yield forecast approach is based on the principle that the number of flowers per unit of area is higher in the most productive years and therefore originating higher airborne pollen concentration (e.g. Besselat and Cour, 1996). Also, according to those previous works, it is hypothesized that airborne pollen enables the integration of the main pre-flowering conditions carried-over from past year(s) which affect fruit production (e.g. hydric, thermal, nutritional and phytossanitary stresses) (e.g. Clingeleffer et al., 2001; Guilpart et al., 2014).

A wine forecast model based on airborne pollen, agronomic and weather conditions after flowering, showed good results in the main wine regions of northern Portugal (Cunha et al 2003). However, it remains unclear the adaptability of airborne pollen based wine forecast models in non-irrigated regions with a strong and extended water and thermal stress during the summer, as well as in regions with a strong increase of vineyard acreage and technological evolution.

Therefore, this study aims to improve and tested a wine forecast model based on airborne pollen for the region of Alentejo, one of the most arid wine regions of Europe and where the vineyard area has greatly increased in recent years. The annual wine forecast was based on a hierarchical analysis, including the estimation of the potential detrended production by the quantification of airborne pollen at flowering through the application of an innovative pollen emission model to calculate the regional pollen index (RPI), followed by the evaluation of the possible impact of fruit-set conditions on the wine production.

\section{Material and methods}

\subsection{Study area}

The work was carried out in the south-eastern region of Alentejo in Portugal (Fig. 1). The landscape of the region is characterized by soft rolling hills and plains. Alentejo wine-growing activity occupies approximately about 24000 ha (7\% of the region), which represent about $8 \%$ of the vineyard surface and around $6 \%$ of the wine production in Portugal. Red grapes dominate, representing $70 \%$ of the planting with high percentage of old autochthonous varieties adequate for dry, hot climate (mostly Aragonez, Trincadeira and Castelão) but also with Shiraz variety increasing in the last years (CVRA, 2015).

\section{[Insert figure 1 about here]}




\subsection{Alentejo Climate}

The region of Alentejo's vineyards is one of the most non-irrigated arid regions of Europe where a strong hydric stress is normally observed during the post-flowering period. These situations are especially frequent in summer and appear as a consequence of the low soil water content, due to the low annual rainfall (300 to 500 $\mathrm{mm}$ ) and the elevated gradients of the water vapour pressure between the leaves and the air (Chaves and Rodrigues, 1987). During the ripening period (20 $0^{\text {th }}$ July to $1^{\text {st }}$ September), precipitation is typically lower than $30 \mathrm{~mm}$, accompanied by high values of solar irradiation, temperature levels and vapour pressure deficit (Reis and Lamelas, 1988).

According to Köppen classification the Reguengos de Monsarraz's climate is a Csa (Mediterranean climate, with dry summer, which is not very hot but extensive), while Thornthwaite's rational climate classification (Thornthwaite, 1948) describes it as: DA's ${ }_{2} \mathrm{sa}^{\prime}$ semi-arid (moisture index: -23.8; D), megathermal (thermal efficiency index: $1210 \mathrm{~mm}$ evapotranspiration; A), with large summer water deficiency (aridity index: 58\%; s2), moderate winter water surplus (humidity index: $11 \%$; s) and summer concentration of thermal efficiency index of $47 \%$ (above $20 \%$; typically continental).

During the period April-October, the mean temperature is about $19.7^{\circ} \mathrm{C}$ and according to the climate grapevine maturity grouping (Jones, 2007), the growing season can be defined as "warm" (April-October; mean temperature between 19 and $24^{\circ} \mathrm{C}$ ).

\subsection{Wine production}

In this work, we use the annual wine production data for the Alentejo region provided by the Comissão de Vitivinicultura do Alentejo (CVRA, 2015). Fig. 2 shows the time series (1996 to 2014) of wine production in Alentejo. There was a marked inter-annual variability in Alentejo wine production, the lowest value of $241 \times 10^{3}$ $\mathrm{hL}$ was observed in 1998, increasing to $1164 \times 10^{3} \mathrm{hL}$ in 2014 (about 5 times the minimum production), which allows the formulation of predictions with a wide validation interval. The time series of wine production data shows that a very large percentage $(70 \%)$ of regional wine production is accounted by the upward trend, i.e. mostly the structure technology, in particular the increase of vineyard surface (CVRA, 2015).

[Insert figure 2 about here]

\subsection{Model development}

\subsubsection{Model calibration}

The wine prediction model tested in Alentejo region was based on the previous model proposed by Cunha et al. (2003b) for the main wine regions of the northern Portugal:

$$
P R D_{i}=\beta_{0}+\beta_{1} \operatorname{Ln}\left(R P I_{i}\right)+\beta_{2} F s_{i}+e_{i}
$$


where PRD $(\mathrm{hL} \times 1000)$ is the annual wine production in the wine region of Alentejo, RPI is the regional pollen index and Fs is the fruit-set conditions. The Fs predictor is a qualitative variable or dummy variable that can assume three levels $-1,0$ and 1 as defined in the next section.

The terms $\beta_{0}, \beta_{1}$ and $\beta_{2}$ are the regression parameters for the intercept and slope respectively. The $e_{t}$ is the stochastic disturbance term of regression (or residue) and $i$ the $i$ th observation (Montgomery et al., 2012).

The regression parameters $\left(\beta_{0}, \beta_{1}\right.$ and $\left.\beta_{2}\right)$ were estimated, using 15 years (1998 to 2014) by the LevenbergMarquard iterative algorithm that requires some reasonable initial values close as possible to the expected final solution (Montgomery et al., 2012). Unfortunately, the airborne pollen data for the years 2010 and 2012 is missing due to technical problems.

We have quantified the contribution of each predictor (RPI and Fs) in the annual wine production, using the stepwise multiple regression technique. A variable was included in the model if the P-value for the Student t_test for that variable doesn't exceeded a critical level of 5\%. At each variable inclusion step, the coefficient of determination $\left(\mathrm{R}^{2}\right)$ value and the change in $\mathrm{R}^{2}$ value were also calculated.

Inferences about the regression parameters $\left(\beta_{0}, \beta_{1}\right.$ and $\left.\beta_{2}\right)$ were checked by the $95 \%$ confidence intervals and the t-tests $(\mathrm{p}<0.05)$ for the null hypothesis of the regression parameters being equal to zero. The $\mathrm{F}$ test $(\mathrm{p}<0.005)$ was calculated to test the significance of the independent variables as a group for predicting the wine production.

The regression mean prediction interval for the $95 \%$ probability level was calculated according to (Montgomery et al., 2012) and was presented graphically in Fig. 5.

\subsubsection{Model's predictors}

\subsubsection{Regional pollen index}

\section{Airborne pollen sampling}

Airborne pollen was sampled by using one Cour trap (A. Eléctrica, V.N.Famalicão, Portugal), located in Reguengos de Monsaraz, Alentejo (400'N, 751'W) over a 15 year period (1998 - 2014) (Fig. 1). Unfortunely, no airborne pollen data for the years 2010 and 2012 are available. The trap was placed at the top of a water tower approximately at $15 \mathrm{~m}$ above ground level. The location of the pollen trap was selected according to the topography and average wind direction during the flowering period. Reguengos de Monsaraz can be considered the geographical centre of the vine growing area of the Alentejo and, during the vine flowering period, receives wind from all directions. The situation is reinforced by the overall flatness of the Alentejo, so that there are no topographic obstacles for the pollen transport.

Pollen grains were trapped on vertical gauze filters $\left(400 \mathrm{~cm}^{2}\right)$ fixed vertically on a wind-vane, which continually orientates the filters according to the wind direction (Fig. 1). During flowering period, filters were exposed for 3 or 4 days. 
After exposure, the pollen grains were removed from the filters using several chemical treatments including the destruction of the gauze, acetolysis and the addition of glycerol for quantification (Cour, 1974). The identification and pollen count was carried out, independently of the pollen grains concentration, with ten regular traverse rows of the optic microscopic (x630). Airborne Pollen Flow (APF) obtained by the pollen captured in each filter exposed for 3 or 4 days, was expressed in number of average daily pollen grains transported per square meter of filter (pollen $\mathrm{m}^{-2}$ ).

\section{Pollen emission model and regional pollen metrics}

A pollen emission model (PEM; eq. 2) was used to extract several metrics related to the main annual pollen season in order to estimate the quantity of pollen that effectively comes from the studied region, avoiding pollen deposition and recirculation as well as the transported pollen from long distances. For this purpose, a logistic regression model developed by Cunha et al. (2015) was fitted annually to the values of the accumulated pollen during the Vitis flowering period:

$y_{t}=\alpha\left[1+\exp ^{-\left(\beta+\gamma x_{t}\right)}\right]^{-1}+e_{t} ; t=1, \ldots, n$

where $y_{t}$ is the amount of accumulated pollen up to day $x_{t}$ referred to the DOY (Julian days of the year); $\alpha$ is the distance between the two asymptotes, representing the value for which the pollen emission is stabilized; $\beta$ is a position parameter; $\gamma$ is the parameter related to the rate of pollen increase; $e_{t}$ is the random model component; and $t$ is the natural number representing the ordinal of observations. The logistic model parameters were estimated by the 'Levenberg-Marquard iterative algorithm.

To obtain the airborne pollen metrics, it was used the pollen emission model's fourth derivative (Cunha et al., 2015) that confirmed the accuracy and precision of these metrics to simulate the dynamic of Vitis flowering observed at the field level in different regions of Portugal. The full details of this pollen model and extraction of the pollen metrics could be consulted in (Cunha et al., 2015). For each year, the airborne pollen metrics were obtained through the dates (DOY) at which the rate of change in the curvature of the logistic model occurs. These changes are inferred by the fourth derivative function zeros $\left(\frac{\delta^{4} y}{\delta x^{4}}=0\right)$ that correspond to the airborne pollen metrics: Start Of Season (SOS), Inflexion Point (IP) or Mean derived Flowering date (MF), and Final Of Season (FOS) (eq. 3 and Fig. 3). It was also determined the Airborne pollen quantity (pollen $\mathrm{m}^{-2}$ ) at the start of the pollen season (ASOS) and at the final of the pollen season (AFOS).

$\frac{\delta^{4} y}{\delta x^{4}}=0 \Rightarrow-1+11 \exp (-\beta-\gamma x)-11(\exp (-\beta-\gamma x))^{2}+(\exp (-\beta-\gamma x))^{3}=0$

where the parameters $\alpha>0$ and $\gamma>0$.

$$
\begin{cases}x_{1}=-[\ln (5+2 \sqrt{6})+\beta] / \gamma & \text { SOS } \\ x_{2}=-\beta / \gamma & \text { IP or MF } \\ x_{3}=-[\ln (5-2 \sqrt{6})+\beta] / \gamma & \text { FOS }\end{cases}
$$


The Fig. 3 presents an example for Alentejo region (year 2004) of the logistic function and its fourth-order derivative function considered to obtain the airborne pollen metrics (SOS, IP and FOS) as well as the RPI and the derived period of fruit-set (PFs). The number of pollen measurements used in the logistic model ranged between 10 and 15 observations depending on the length of the pollen season in each year (Table 1).

The Regional Pollen Index (RPI; pollen $\mathrm{m}^{-2}$ ), which is used in the forecast model, is calculated from the sum of the amount of pollen obtained during the main pollen period (AFOS - ASOS). The airborne pollen metrics extracted from the PEM are also used to define the derived period of fruit-set period (see next section).

[Insert figure 3 about here]

\subsubsection{Fruit-set meteorological conditions}

The derived period of Fruit-set (PFs), was considered from IP date to 20 days after FOS and extracted from the logistic model. The annual start date and the length of the PFs, that was defined according to Cunha et al. (2003b), is used in the forecast model for the assessment of the climate impact during this period on the wine production.

The impact of the meteorological conditions during the flowering to fruit-set period $\left[\mathrm{IP}_{\mathrm{x}} ;\left(\mathrm{FOS}_{\mathrm{x}}+20\right.\right.$ days $\left.)\right]$ on the regional production levels was evaluated through a qualitative variable (Fs) that assumes three categories (1, 0 and 1) as discussed by Cunha et al. (2003b):

- Very unfavourable conditions (Fs=-1): when the number of consecutive days with mean temperature $<15^{\circ} \mathrm{C}$ are $>4$ days and the occurrence of consecutive rainy periods are $>4$ days during the considered period (PFs).

- Unfavorable conditions ( $F s=0$ ): when one of the previous conditions is verified in terms of number of consecutive days with mean temperature $<15^{\circ} \mathrm{C}$ or $>4$ consecutive rainy days during the considered period.

- Favourable conditions ( $\mathrm{Fs}=1$ ): characterized by the absence of periods of consecutive rainy days, temperatures are always $>15^{\circ} \mathrm{C}$ and the percent of rainy days $<30 \%$.

Our modelling assumption is that temperatures between 17 and $25^{\circ} \mathrm{C}$ and the absence of lengthy periods of rain during the derived fruit-set period, facilitate rapid pollen emissions and their high concentration in the atmosphere, pollen tube growth, ovary fertilization, and fruit set (Carboneau and Ollat, 1993; May, 2004; Vasconcelos et al., 2009). Spells of continued rain with temperatures lower than $15^{\circ} \mathrm{C}$ during this period causes washing of airborne pollen and difficulties with the normal opening of the flower cap that prevents the stamens from spreading out and facilitates agglomeration of the pollen grains. These meteorological conditions decrease sunshine and photosynthetic assimilation and result in poor fruit set (Carboneau and Ollat, 1993; Ebadi et al., 1995; May, 2004; Vasconcelos et al., 2009). 
227 Daily meteorological observations for the years 1998 to 2014 from the weather station located in Reguengos de 228 Monsaraz ( $38^{\circ} 26^{\prime} \mathrm{N}, 7^{\circ} 33^{\prime} \mathrm{W}, 210 \mathrm{~m}$ above the sea level), about $5 \mathrm{~km}$ from the airborne sampling point were 229 used. This weather sation is under the responsibility of the Centro de Geofisica de Évora.

\section{2.4.3. Detrending process of data}

231 In Alentejo, an upward long-term trend is observed in the wine production time series that is mainly a reflection 232 of the increasing in production area (Fig. 2). The last implies an increase in the number of plants producing 233 pollen and, therefore, an upward trend in the RPI is also expected. In fact the RPI presented an upward trend 234 during the studied period $\left(\mathrm{R}^{2}=0.325, \mathrm{n}=15 ; \mathrm{p}<0.05\right)$.

235 Therefore, to avoid spurious association between time series (wine production and RPI), both variables were detrended before performed the regression (eq. 1). Assuming the linearity of the time trend, the detrending was performed by three- stage procedures (Gujarati, 1995; Ye et al., 2015): i) first we regressed the wine production on time (year) and obtained the residuals from this regression, say $\hat{u}_{l t}$, ii) second, we regressed RPI on time (year) and obtained the residuals from this regression, say $\hat{u}_{2 t}$ and finally, iii) we regressed $\hat{u}_{1 t}$, on $\hat{u}_{2 t}$, which are both free of the influence of time trend.

\section{2.4.4.1. Cross validation}

243 It was used a cross- validation method to estimate how accurately the predictive model would perform in practice (Picard and Cook, 1984). The cross validation was performed on the 15 observations available fo the period (1998-2014) using the "leave-one-out" (LOO) cross-validation method. The LOO cross-validation evaluates the model performance for observations not considered in the calibration step, thus providing independent estimates of the predictive capability of the selected model. This technique consists in the removal of one observation (year) of wine production from the dataset used and the estimation of a new regression model with the remaining observations. This new regression model is then used to estimate the wine production of the year previously withdrawn.

\subsubsection{Validation measures}

No single parameters based on comparison betwen observed and modelled values is sufficient to adequately assess the goodness-of-fit or the model's performance. Nevertheless, each criterion highlighted particular aspects of the comparison (Tedeschi, 2006). In this work, following Bellocchi et al. (2010) and Moriasi et al. (2007), the validation measures were divided into two main categories: i) hypothesis testing or model assumptions measures and ii) measures of goodness-of-fit. The last was subdivided into groups of measures: i) association or regression and ii) error indices.

258 These model validation measures are calculated for both calibration and cross validation data-sets. The process 
260 goodness-of-fit indicators relative to the validation are of a magnitude similar to those relative to the 261 calibration.

\section{2.4.4.2.1. Model assumptions testing}

263 For the hypothesis testing evaluation, both graphical and statistical evaluation techniques were used.

264 Graphical analysis

265 Methods suggested by Altman and Bland (1971) were applied to the data to evaluated the disagreement 266 between actual and modelled wine production and the relative contribution of bias and error. The differences 267 between observed and modelled data were plotted against their average for visual assessment of bias and error, 268 thus allowing to spot outliers and to see whether there was any tendency for the amount of variation to change 269 with the magnitude of the wine production.

270 Assumptions based in the residuals

271 The leverage test was used to detected influential observations. This test was performed for both calibration and 272 cross-validation data-set and the maximum value accepted for the leverage test was 1.5 (Montgomery et al., 273 2012).

274 We assume that the residual $e_{i}$ follow the normal distribution with zero mean and constant variance; $e_{i} \sim \mathrm{N}(0$, $\left.275 \sigma^{2}\right)$.

276 The assumption of the normal distribution of the residual was assessed by the Jarque-Bera test (Gujarati, 1995).

277 The Breusch-Pagan test (Breusch and Pagan, 1979) was used to identify homoscedasticity by testing the 278 dependence of the variance of residuals on the values of independent variables. In both tests, the null hypothesis 279 is that the variance of the residuals are homogenous or the residuals are normally distributed, respectively. 280 Therefore, if the p-value is lower than $5 \%$ for $\chi_{(2 \mathrm{df})}^{2}$ distribution, we reject the null hypothesis.

281 2.4.4.2.2. Goodness-of-fit measures

282 The goodness-of-fit indicators (association and residual based) used for calibration and validation data-sets, 283 were selected following previous modelling studies discussed, among other, by Legates and McCabe (1999), 284 Hyndman and Koehler (2006), Tedeschi (2006), Moriasi et al. (2007) and Pereira et al. (2015) They consisted 285 of:

286 Association measures

287 The association measures provide a relative estimate of the co-variation or association between observed and 288 estimated values. These standardized measures were performed on the detrended data for both calibration and 289 cross validation data-sets:

290 - Coefficient of determination $\left(\mathrm{R}^{2}\right)$ describes the proportion of the total variance in the annual wine production 291 (observed data) that can be explained by the model's independent variables. We used $\mathrm{R}_{\text {LOO }}^{2}$ to show the 292 proportion of variance explained by cross validated predictions. 
- A linear regression through the origin between detrended pairs of actual and modelled wine production was performed. The hypothesis is that the concordance line of this regression passes through the origin and has a coefficient of regression $\left(b_{0}\right)$ of unity. In this regression the use of R2 for model performance is flawed as it does not account for model bias (Bellocchi et al., 2010; Tedeschi, 2006).

- Nash-Sutcliffe model efficiency coefficient (NSE) is a normalized statistic that compares the relative magnitude of the residual variance against to the observed data variance (Nash and Sutcliffe, 1970). NSE can range from $-\infty$ to 1 . Essentially, the closer the model efficiency is to 1 , the more accurate the model is. The NSE compared with the $\mathrm{R}^{2}$ is less sensitive to differences in the observed and modeled means and variance. However, NSE and $\mathrm{R}^{2}$ are both overly sensitive to extreme values (Legates and McCabe, 1999).

\section{Residual indices}

A set of errors indices was also computed for model evaluation (e.g.Moriasi et al., 2007): the root mean square error (RMSE), the average absolute error (AAE), the average relative error (ARE) and the percent of bias (PBias). The errors indices are, very useful in the model's performance analysis because they indicate errors in the same units (AAE, RMSE) or percentage (ARE and PBias) of the observed data. These no standardized measures are considered stand-alone accuracy measures because they can be obtained without additional reference.

Both RMSE and AAE measure the distance of the forecast error with no distinction between positive and negative forecast errors. For RMSE that is due to squaring the forecast error, in contrast to AAE which uses the absolute value. The ARE presents the error in terms of percentage, hence, it is not, invariant to scale transformations (Hyndman and Koehler, 2006).

The Percent bias (PBias) measures the average tendency of the simulated values to be larger or smaller than their observed ones. The result is given in percentage (\%). The optimal value of PBias is 0.0, with lowmagnitude values indicating accurate model simulation. Positive values indicates overestimation bias, whereas negative values indicate model underestimation bias.

Despite the intuitively usefulness of these error indices, they are not invariant to scale transformations. Also, they are symmetric, a property which is not very realistic and inconceivable under some circumstances such as the detrending procedure (Hyndman and Koehler, 2006). Therefore, the time trend of wine production, which was initially removed from the data, was then added back to obtain the real predicted errors (RMSE, AAE, ARE and PBias). The real predicted errors was then compared with the actual data of wine production to evaluate the prediction accuracy based on scale dependent errors.

\section{Results}

\subsection{Statistics of model's variables and meteorological conditions throughout the grapevine cycle}


Table 1 presents the descriptive statistics for the variables used in the wine predictive model and the meteorological conditions which occurred during the grapevine cycle in Alentejo over the period studied (19982014).

The 15 years mean wine production (1998 to 2014; lack of data for 2010 and 2012) averaged 764 x $10^{3} \mathrm{hL}$ with a coefficient of variation of $33 \%$. The interannual variability of RPI (c.v. 61\%) was much higher than the wine production, which indicates the need to perform transformation in the independent variable in order to meet the assumption of model homoscedasticity (Table 1). Therefore, as suggested by Cunha et al. (2003b) a lntransformation on the RPI dependent variable was performed

The pollen emission model, used to extract several metrics related to the annual main pollen season (MPS, Fig 3), presented a coefficient of determination that was always greater than 0.96 ( $\mathrm{p}<0.01$; data not showed). According to this model, there was a marked inter-annual variability in the pollen season dynamic. The derived SOS date (Fig. 3) date was the DOY 129 and ranged from DOY 118 to 138. The mean derived flowering date (IP; Fig 3) was the DOY 137, ranging from 132 to 146 and the duration of MPS extends from 8 to 28 days, which represents a great inter-annual variation (coefficient of variation of $32 \%$ ).

The mean rainfall registered during the budburst-flowering period $(93 \mathrm{~mm})$ represented $18 \%$ of the annual mean and $71 \%$ of rainfall during the budburst-harvest period. The temperature during the flowering to fruit-set derived period ranged between 18 to $24^{\circ} \mathrm{C}$, which facilitated rapid pollen emissions into the atmosphere, pollen tube growth, ovule fertilization and fruit set.

Table 1 also presents the impact on the wine production of the meteorological conditions during the flowering fruit-set derived period using the proposed qualitative variable Fs. Only two years (1998 and 2002) presented very unfavourable meteorological conditions during the flowering to fruit-set period $($ Fs $=-1)$, while favourable conditions $(\mathrm{Fs}=1)$ corresponded to most of the crop seasons studied (60\% of the years). The years with the lowest temperature (1998: $18^{\circ} \mathrm{C}$ and $2002: 19^{\circ} \mathrm{C}$ ) during flowering to fruit-set period were associated with spells of continuous rainy days (\%nR: $46 \%$ in 1998 and $32 \%$ in 2002).

[Insert table 1 about here]

\subsection{Model calibration and parametrization}

Predictors and their corresponding regression coefficients for the improved pollen based predictive model of wine production tested in Alentejo for the period 1998-2014 (15 observations) are presented in equation 4:

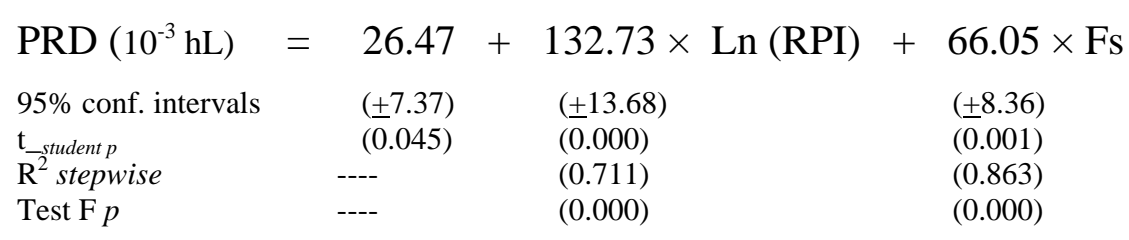


The intercept term $\left(\beta_{0}\right)$, and coefficient of RPI and Fs are significantly different from zero on the basis of $t$-test at $5 \%$ level (eq. 4). Also, the $95 \%$ confidence interval of the regression parameters not containing zero which imply that they are statistically significant.

The $\mathrm{R}^{2}$ stepwise represents the $\mathrm{R}^{2}$ of the regression and the respective statistical significance (Test $\mathrm{F} p$ ), when each model predictor was added to the model using the stepwise method. The model is statistically significant on the basis of the F test $(\mathrm{p}<0.000)$.

According to equation 4, both RPI and Fs coefficients are positive and thus consistent with what would be expected for their impact on wine production. Hence, an increase in the airborne pollen and/or hot and dry conditions during the fruit-set period results in an increase in the wine production in Alentejo.

The equation shows a satisfactory fit with R2 values of $0.71(n=15 ; p<0.000)$ for the RPI, which increased to $0.86(\mathrm{n}=15 \mathrm{p}<0.000)$ when the Fs variable was added to the model. This means that approximately $86 \%$ of the interannual variability of wine production in Alentejo can be explained by these predictors.

\subsection{Analyse of validation measures}

Table 2 presents the results for the basic assumptions and goodness-of-fit indicators for the model calibration and model validation data-sets.

[Insert table 2 about here]

Fig. 4 presents the differences between actual minus modelled wine production plotted against the actual wine production. The differences spread on both sides of the "zero line" with no tendency of the residuals.

\section{[Insert figure 4 about here]}

The leverage statistics to detect influential observations presented in table 2 do not exceed the cut-off limit (1.5) defined by Montgomery et al. (2012).

The Jarque-Bera test P-value is reasonably high for both calibration ( $\mathrm{p}>0.630)$ and validation $(\mathrm{p}>0.459)$ datasets, one does not reject the hypothesis that the residual are normally distributed. The presence of homoscedasticity in the residuals was confirmed from the P-value of the Breusch-Pagan tests for the calibration ( $\mathrm{p}>0.630)$ and validation $(\mathrm{p}>0.459)$ data-sets (table 2$)$.

The model diagnostic tests show that the residuals satisfy the basic regression assumptions of no serial correlation, homoscedasticity and normality.

The wine forecasting model developed for Alentejo accounts for $86 \%$ of the regional wine variability over the years (Table 2) with a standard error of estimate of $49.8 \mathrm{hL}$ x $10^{3}$. The leave-one-out cross validation, indicates that the model would be about $81 \%$ accurate in predicting wine volume production. Furthermore, when the linear trend was added to the modelled wine production the percentage of explained variance rises to $98 \%$ and 96\% respectively for the calibration and validation data-sets (not showed).

The good-ness-of-fit indicators based association measures show a very good agreement between detrended observed and modelled wine production, with regression coefficients through the origin (b0) close to 1.0 , 
indicating that the predicted and observed values were quite similar. There is absence of bias in the calibration data and a very slight under-estimation bias in the validation data-set (b0=0.946; Table 2). The R2 of 0.836 and 0.790 , respectively, for the calibration and validation data sets, indicates that most of the observed annual wine production was explained by the model (table 2).

The NSE is very close to 0.80 in both calibration and validation data-sets, which indicating that the variance of residuals is much smaller than the measured data variance of wine production.

The PBias was values close to zero in both calibration and validation data-sets, indicating the absence of bias and accurate model predictions. These results are in line with the residuals plotted in Fig. 4 and the results of the regression through the origin (table 2).

The estimation errors were low, with AAE of 31.3 and $37.9 \times 10^{-3} \mathrm{hL}$ for the calibration and validation date-sets respectively, which corresponds to an ARE lower than 6\% (Table 2). For the 15 years of cross-validation data records, the ARE shows that, about $87 \%$ of cases had differences between actual and modelled wine production below 10\%, being the highest deviation of 13.1\% observed in 2000 and 2004 (Fig. 5). However, these largest deviations are consistently inside the prediction interval (Fig. 5).

The RMSE was low and consistent in the calibration $\left(40.9 \times 10^{-3} \mathrm{hL}\right)$ and cross-validation $\left(48.8 \times 10^{-3} \mathrm{hL}\right)$ datasets. The RMSE and AAE presented similar values indicating the existence of low variance in the differences between the modelled and observed data.

Overall, these indicators show a good performance of the predictions of wine production.

[Insert figure 5 about here]

\section{Discussion}

\subsection{Reliability and early-indication ability of pollen based model}

The Alentejo regional wine production was forecasted using the RPI and climate conditions during the derived fruit-set period, describing about $86 \%$ of the regional wine variability over the years with a standard error of estimate of $49.8 \mathrm{hL} \times 10^{3}$. The impacts of pre-floral and floral conditions impacts on wine production were represented by a RPI derived from a logistic airborne pollen emission model (PEM). By updating the wine production estimates as the season progresses with the derived fruit-set period climate conditions, improved estimation accuracy was achieved. The RPI was the variable with larger explanatory capacity $(\mathrm{R} 2=0.71)$ of annual variability in wine production and approximately $15 \%$ of this variability could be explained by Fs (R2 increased from 0.71 to 0.86 ). The leave-one-out cross validation, indicates that the wine forecasting model is about $81 \%$ accurate in predicting wine volume production, which is a strong evidence that the developed model satisfactorily predicts the regional wine volume.

The goodness-of-fit indicators support that the variation of the observed wine production throughout both calibration and validation data-set is well explained by the predictive model. The model calibration and validation showed a mean ARE lower than $6 \%$ and the maximum percentual difference for the studied period 
was $13.1 \%$. The accuracy and precision of this model make it a useful tool for the governmental agencies and wine industry.

\subsection{Biophysical sense of the model predictors and grapevine sensibility}

\subsubsection{Relationship between airborne pollen and grapevine yield components}

Around $71 \%$ of the Alentejo regional wine production for the period 1998-2014 (15 years) could be explained at the time of flowering by the RPI. Previous works, relating the relative importance of each grape yield component on future yield, have consistently demonstrated that the components cluster per vine and number of berries per cluster explain, respectively $60 \%$ and $30 \%$ of the inter-annual variation in vine yields, respectively (Clingeleffer et al., 2001; Guilpart et al., 2014). The berry weight, closely related to the berry size, explains $10 \%$ of the yield variation but is dependent on both the field environment and wine-making techniques at the winery. Therefore, in our study, the predictor RPI used in the forecasting model is biophysically sound and can be supported by the relation between pollen counts and both cluster and flowers number per vineyard surface. Between 1989 and 1997, through the aforementioned project MARS, a network of 46 pollen traps were installed in order to forecast several perennial crops (grapevine included) at regional scale in several countries of Europe based on airborne pollen concentration (Besselat and Cour, 1996). In this network, often the results were not satisfactory since $20-60 \%$ of interannual variability in production could not be explained solely by pollen (Besselat and Cour, 1996; Cour and Van Camp, 1980; Cunha et al., 2003b). Those results should be relativized by the low number of observations used to model calibration and the lack of model validation.

In the literature, several models using airborne pollen data for harvest prediction have been developed with percentage of explained interanual variability in production between 20 and $80 \%$, being in our study case of $71 \%$.

The difference in performance presented by such models, can be due to the different approaches used to calculate the regional pollen index (RPI). Therefore, the accurate estimation of the main pollen season (beginning and final) and of RPI as defined in Cunha et al. (2015), is important to determine the quantity of pollen that effectively contributes to local pollination avoiding pollen deposition, recirculation and long distance transport that increase the RPI.

\subsubsection{Impact of meteorological conditions during the fruit set}

In accordance with the wine forecasting model, very unfavourable meteorological conditions during the flowering to fruit-set period (Fs=-1) have a negative impact on the Alentejo wine production of about $66 \times 10^{3}$ $\mathrm{hL}$ (eq. 4), that represents maximum production losses of $16 \%$ relative to the mean wine production in Alentejo. This result is similar to the ones reported in previous works for other wine regions where the very unfavourable climate conditions during the fruit-set period can cause maximum losses of $21 \%$ in the annual wine production (Cunha et al., 2003b). 
In addition to positive impact of dry and hot conditions on fruit-set (Fs $=1)$ one should consider the duration of the productive cycle of grape vine. In fact, while these conditions might favour the fruit-set (e.g. May, 2004), they could also shorten the length of crop cycles, thus with great impact on grapevine stress avoidance and, consequently on wine production (Urhausen et al., 2011).

\subsubsection{Impact of post-flowering conditions on wine production}

The improved pollen based model used in our study reveals the very low influence on wine production of postflowering abiotic factors, such as water stress, as well as other biotic ones (e.g. diseases) relative to the influence of those that affect flowering and fruit-set periods. Nevertheless, these results do not mean that the regional wine production is independent of what happens between the fruit-set and the harvest period.

Alentejo is one of the most arid wine regions of Europe, with conditions of high water stress in summer. However, this hydric stress is consistent among years (Chaves and Rodrigues, 1987; Reis and Lamelas, 1988). In the Alentejo region, as in many other wine regions, relatively wet and hot weather episodes that favour diseases (Pearson and Goheen, 1990) occurred mainly during the pre-flowering period (Kennelly et al., 2005) and its effects on production level could be evaluated by RPI (Fernandez-Gonzalez et al., 2011a). So, it is difficult to consider the post-flowering conditions, after the fruit-set period as a relevant factor causing interannual fluctuations in wine production. These characteristics confirm the results obtained in Portugal (Cunha et al., 2003a) and for the European pollen-traps network (Besselat and Cour, 1996), suggesting a lesser applicability of the wine forecast models based on pollen analysis in vineyard regions where the interannual variations in water supply significantly account for deviations in the final yield compared to the early crop yield determined at flowering.

On the other hand, in regions with rainy post-flowering period and great interannual variation in water stress, additional parameters, such as disease occurrence, agronomic, and weather conditions after flowering, should be foreseen (Cunha et al., 2003a; Fernandez-Gonzalez et al., 2011a; Fernandez-Gonzalez et al., 2011b).

Therefore, the pollen based model tested in our study could be enhanced by a hierarchical analysis, including the quantification of the RPI at flowering and climate conditions during the fruit-set period, followed by the application of remote sensing techniques (Bellvert et al., 2014; Hall et al., 2002) in order to determine the impact of post-flowering biotic (e.g. phytopathological stress) and abiotic factors (e.g. hydric stress) on limiting the potential production acquired at fruit-set .

In Alentejo, the occurrence of continuous periods of rain during the vintage precludes the harvest in some vineyards. The developed forecast model did not account for this variation. However, as the impact on crop size of abnormally extended wet period during the vintage can only be known a short time before harvest, its inclusion in the model would imply a loss of forecast opportunity, decreasing the model's usefulness.

\subsection{Spatio-temporal adequacy and operationality of pollen based models}

\subsubsection{Number of pollen traps at regional level}


494

495

496

497

498

499

500

501

502

503

504

505

506

507

508

509

510

511

512

513

514

515

516

517

518

519

520

521

522

523

524

525

526

Most of the pollen captured by a trap during the grapevine flowering period comes from the vineyards growing in the area around the trap ("the area of influence"). The size of this area depends upon several conditions such as pollen type, vegetation distribution, meteorological factors, topography, height of installation of the trap and the relative acreage occupied by vineyards (Besselat and Cour, 1996; Rojo et al., 2015; Scheifinger et al., 2013).

It is not possible to determine exactly the area of influence of an airborne pollen sampler. Previous studies on phenology have indicated that a sampler detects pollen grains from a crops located up to $50 \mathrm{~km}$ around its position (Belmonte et al., 1998). Regardless of the grapevine area, in some wine regions it might be needed the installation of more than one pollen trap. For example, in flat wine regions such as Cognac and Saint-Emillion in France one pollen trap has been used to predict the wine production in these regions (Besselat and Cour, 1996). However, in mountainous regions with several valleys such Douro (Portugal) and Champagne (France) it is used, respectively, 2 pollens traps (Cunha et al., 1999) and 4 pollens traps (Perry et al., 2015) to predict the wine production at sub-region level. Moreover, the number of the pollen traps within one wine region depends also on the scale of the assessment of the official statistics of wine production that are generally performed at the wine region as a whole. Therefore, a predictive model for sub-region level may be unusable due to the unavailability of required wine production data at the relevant spatial scale.

\subsubsection{Operability of the pollen based model}

The main disadvantages of wine forecast models based on airborne pollen samples are the number of RPI observations (years) needed to accurately calibrate the model and the expensive and complex laboratory process involved in the pollen analyses. Moreover, pollen based predictive models are not a useful technique for wine production for individual patches of vines or even varietal yields from within a region.

The number of observations required for model estimate increase with the number of parameters to be estimated, and the amount of randomness in the data. For example, the agrometeorological models developed for wine forecast are frequently based on a high number of climate variables that (see next section), consequently, requires a high number of years ( $>30$ ) for model calibration. The low number of parameters (RPI and Fs) used in the model tested is one advantage in terms of number of observations required for parameters estimation. However, contrarily to the climate data, the historic regional pollen data aren't available, which requires some years to record the pollen data before the model estimation.

According to Ortega et al. (1998), based on the historic data of wine production, it is possible to estimate a wine forecast model based on airborne pollen after three years of operation since the years available were not atypical in terms of agro-climatic conditions. However, the predictive power of this model is low and should be only used qualitatively to indicate whether the production will increased or decreased in comparison with the previous year. Hence, a period of at least 6 to 8 years according to the inter-annual variability of the wine 
production in the region, will probably be required to obtain predictive results with acceptable accuracy (Besselat and Cour, 1996; Cour and Van Camp, 1980; Cunha et al., 1999).

The main constrains related with the laboratory processing of the samples are the chemical procedures to extract the pollen from the filters and their microscopic identification, needing about 7 hours per filter.

The use of new techniques based on image processing (e.g. Lagerstrom et al., 2015) or DNA analysis (e.g. Rittenour et al., 2012) could be an important step for the improvement of the use of forecast models based on airborne pollen.

\subsubsection{Impact of vineyard dynamic acreage on pollen sampling}

The annual pattern of pollen emission and the amount of pollen captured annually may change as a result of changes in the environmental biophysical conditions around the pollen trap (Ribeiro et al., 2007a; Scheifinger et al., 2013). Such is for example the case of the presence of obstacles (trees, buildings etc) near the pollen trap, modification of the vineyard acreage or the relocation of the pollen trap (Besselat and Cour, 1996).

The pollen trap located within the Alentejo region was not relocated over the studied period, but the regional vineyard area had a large increase (CVRA, 2015) as reported by the increase of wine production (Fig. 2).

A drawback for wine production forecast in Alentejo region, as in many other regions worldwide, is the lack of annual detailed regional data of the dynamics of new plantings, replanting, removal and age composition of vineyard. In this context, our modelling assumption was that the dynamic of new planting and age composition in the studied region were reasonably uniform over the trap for not jeopardise the regional representativity of the pollen sample. This assumption is acceptable since the annual pattern of pollen emission and the amount of pollen are comparable among the studied years in Alentejo (data no showed). In fact the interannual variability of the RPI presented a coefficient of variation of $61 \%$ (table 1), which is similar to the coefficient of variation of the RPI for other wine regions in Portugal (Cunha et al., 2003b).

The inherent difficulty in obtaining a detailed annual record of vineyard surface dynamic for wine production forecasting purposes can be overcome by the use of the RPI and detrending data.

In Cordoba province, García-Mozo et al. (2014) reported a positive linear trend in the regional Olive pollen which is correlated with the increase on land surface of Olive trees in this region (García-Mozo et al., 2014). This trend describes the temporal change in the average value of a targeted variable that embodies the changes of technological progress, the long-term environmental change and crop surface among other factors. Thus, the RPI has the advantage to give an easy updating of the regional vineyard surface development, since it is based on the assumption that a higher number of plants per area produce more inflorescences, which in turn, produce more pollen, thereby generating a higher RPI at flowering period.

As outlined for the Alentejo region, an upward linear trend was also documented for other wine regions such as Douro (Cunha and Richter, 2012), Bordeaux (Jones and Davis, 2000) and California ((Lobell et al., 2007). Failures in trend identification in crop yield prediction models such as those based on pollen as a descriptor, are 
a major source of error causing misleading results in subsequent applications (Fernandez-Gonzalez et al., 2011a; Fernandez-Gonzalez et al., 2011b; Ribeiro et al., 2007b). For instance, if one were to regress wine production and airborne pollen, the expected high value of explained variance my not reflect the true association between these variables; it may simply reflect the common trend present in them. Detrending is particularly important for many agronomical purposes such as crop yield risk assessment and insurance ratings (e.g. Ye et al., 2015), climate change (e.g. Reidsma et al., 2010), crop modelling (e.g. Cunha and Richter, 2012) and crop yield forecasting (e.g. Qian et al., 2009). However, in contrast with the distribution problems such as normality and homoscedasticity, the influence of trend models has been largely neglected in the crop yield forcast models (Finger, 2010; Ye et al., 2015).

To avoid spurious association between wine production and RPI time series, in this work the trend were removed by subtracting the fitted linear regression value from the observed data, but the trend was added back for the estimation of some validation measures.

Various methods to describe the linear time trend of crop yield have been tested by Palm and Dagnelie (1993) and the conclusion was that a simple linear time trend is sufficient in most cases to develop the yield crop forecast models. The performance of crop yield detrending techniques were also presented in Ye et al. (2015).

\subsection{Value added of the pollen based models to the wine prediction}

The predictive results for the Alentejo wine production are comparable with those obtained for other pollen based models developed for Olive under Mediterranean conditions (e.g. Oteros et al., 2014; Ribeiro et al., 2009). However, this predictive results should be relativized in terms of variance explained, since the trend observed in production was not removed from the model (e.g. Oteros et al., 2014)

Predictive models based on grapevine yield components are currently the basis of most yield estimating procedures. Preliminary research developed in France (Huglin and Schneider, 1998), Australia (Dunn, 2010), United States of America (Sabbatini and Howell, 2012) and Spain (de la Fuente et al., 2015) have showed that for grapevine yield forecasts based on bunch counts in spring alone we can expect an AAR of $20 \%$ and for forecasts based on berry counts after fruit-set the AAR decreased till 10-15\%. Although designed for yield prediction at the field scale, this approach could be used to estimate grapevine yields at broader scales, given attributes representative of the area, grapes varieties, phenology and an appropriated means of aggregation (Clingeleffer et al., 2001). However, the effects of spatial averaging of inputs to the model, such as soil characteristics, crop systems and spatial extrapolation of model yield predictions, remain unclear. Therefore, this approach could be important to predict the wine production at farm or variety levels, however it's still unknown their performance to predict the production at regional level.

Several agrometeorological models have been developed for wine forecast, using a number of climatic variables or climatic indices throughout the grapevine cycle (Cunha and Richter, 2012; European Commission, 1997; Fraga et al., 2014; Palm and Dagnelie, 1993; Quiroga and Iglesias, 2009; Santos et al., 2013). Such models are 
able to explain between 40 to $80 \%$ of the inter-annual variability of the regional wine production but included a large number of variables (up to 15), which are quite different among models, and some of the predictors are not biophysical sound. Therefore, the lifetime or durability of these models is, generally, too short. The lack of robustness of the agrometeorological models may reflect a weak explicit link to grapevine biophysical processes in the construction of the mathematical relationship as suggested by Bellocchi et al. (2010).

The low accuracy of sevral of these agrometeorological models could be related with the long reproductive phase of grapevine (18 months) that begins in one season and is not completed until the next one (Vasconcelos et al., 2009). During this period there is a set of critical events that determine the potential yield and its realization. These events are highly sensitive to environmental and cultural factors, but their impact on grape yield, despite the large amount of work done, remains poorly understood (Cunha et al., 2010; Guilpart et al., 2014).

As referred, the RPI explained $71 \%$ of interannual variability of the wine production, which is notable because a single biological or abiotic predictors used in the agrometeorological or grapevine components based models for predicting the production, as we know, never reaches values close than this. Since the RPI could be known 3 to 4 months before harvesting, its inclusion in a model would imply an increase in the forecast opportunity and therefore, in the model's usefulness.

Overall, the robustness, reliability and timely ability of the improved pollen based model tested in our study contributes to enlarge the alternatives for wine prediction, overcoming some of the drawbacks of the models aforementioned.

An important issue for the model's accuracy and, probably for its generalization, it is the determination of the exact RPI that contributes to the effective pollination and that is provided by the pollen emission model. Our results improve the knowledge about the abiotic factors responsible for crop production and propose the applicability of the tested model to wine regions characterized by strong hydric stress during the post flowering period.

This study also confirmed the relationship between the increase of vineyard surface and the RPI. Therefore this model could be applicable at regions with high dynamics of vineyard acreage, but appropriate detrending-data process should be needed.

The results achieved are a major contribution to the knowledge about the pollen based predictive models reliability under different sets of experimental conditions.

\section{Conclusion}

The pollen-based predictive model tested in our study is a valuable instrument for vintage forecasts because of the integration of the major biological determinants of gravepvine yield and simultaneous update of the dynamic of regional vineyard surfaces. The wine production could be predicted 3 to 4 months before harvest, 
which is still useful for the wine industry as the official statistics of wine data in most countries are not available until December, about 6 months after the model predictions.

The predictive results of the improved model tested in our study showed that under conditions of high frequency of strong hydric stress in summer, there is very low influence on the wine production of postflowering factors relative to those that affect flowering. Thus, this model can be used to forecast vintages in many other non-irrigated viticultural arid zone, wherein a large part of the world's vineyards are planted. However, in regions with a rainy post-flowering period and great interannual variation in water stress, additional parameters, such as disease occurrence, agronomic and weather conditions after flowering, could be needed.

Pre-floral and floral conditions impact in wine production was represented by a regional pollen index derived from airborne pollen monitoring, giving the first estimate of potential production at the time of flowering. Nonetheless, despite the airborne pollen sampling protocol being well established, different methods to calculate the regional pollen index are used. Defining the RPI variable based on standardized methodology is an expedient and reliable mean of improving the accuracy of the European forecast network, whose great investment in pollen samples is at present restricted in practical application.

The reliability and early-indication ability of these forecast models justify their use to support decision-making process and improve the agronomic and economic efficiency of vineyard and winery operations. Also, similar models based on airborne pollen can be used for the prediction of regional production for other crops, such as Olive, Hazel and Coffee, as the number of flowers per plant is also the key component factor of the yields for these crops.

\section{Acknowledgments}

The authors would like to thank Dora Simões, CVRA Comissão de Vitivinicultura do Alentejo (CVRA) and Francisco Mata, Associação Técnica dos Viticultores do Alentejo (ATEVA) for assist the pollen collection and climate data. H. Ribeiro benefits from a scholarship (SFRH/BDP/103934/2014) financed by QREN-POPH and FCT.

\section{References}

Abid, A., 1991. Contribuition à l'etude de la pollinisation de l' olivier (Olea europea L.) et du clementier (Citrus reticulata B.). Utilization des données pollinique comme indice prévionnel des récoltes à l' échelle locale et régionale, Université de Montepllier II, France.

AGRI4CAST, 2015. Crop Yield Forecasting System, Available online at http://mars.jrc.ec.europa.eu/mars/Aboutus/AGRI4CAST (assessed 2 April 2015), Joint Research Center, Institute for environment and sustainability (IES).

Altman, D.G. and Bland, J.M., 1971. Measurement in medicine: the analysis of method comparision studies. Statistician(221): 850-892.

Bellocchi, G., Rivington, M., Donatelli, M. and Matthews, K., 2010. Validation of biophysical models: issues and methodologies. A review. Agronomy for Sustainable Development, 30(1): 109-130.

Belmonte, J., Canela, M., Guardans, R. and Roure, J., 1998. Comparison of pollen data obtained by Cour and modified Durham methods. . Pollen and Spores, 30(2): 257-264. 
Besselat, B. and Cour, P., 1996. Early crop prediction. Summary and prospects for the use of a new tool based on pollen analysis of the atmosphere. . In: J. Dalleman and P. Vossen (Editors), Agrometeorological Models: Theory and Applications in the Mars Project Official Publications of the European Communities, Italy, ISPRA, pp. 73-82.

Bindi, M., Fibbi, L., Gozzini, B., Orlandini, S. and Miglietta, F., 1996. Modelling the impact of future climate scenarios on yield and yield variability of grapevine. Climate Research, 07(3): 213-224.

Blom, P. and Tarara, J., 2009. Trellis tension monitoring improves yield estimation in vineards. HortScienc, 44: 678-685.

Breusch, T.S. and Pagan, A.R., 1979. A Simple Test for Heteroscedasticity and Random Coefficient Variation. Econometrica, 47(5): 1287-1294.

Carboneau, A. and Ollat, N., 1993. Ètude de la coulure et maîtrise de la production. Progrès Agricole et Viticole, 15: 331339.

Chaves, M. and Rodrigues, L., 1987. Photosynthesis and water relations in grapevines response to environmental factors. In: J.D.e.a. Tenhunen (Editor), Plant Response to Stress-functional analises in Mediterranean Ecosystems. Springer Verlag, Berlin, pp. 279-290.

Clingeleffer, P., Dunn, G., Krstic, M. and Martin, S., 2001. Crop development, crop estimation and crop control to secure quality and production of major wine grape varieties: A national approach, Australian Grape and Wine Authority.

Cola, G. et al., 2014. Description and testing of a weather-based model for predicting phenology, canopy development and source-sink balance in Vitis vinifera L. cv. Barbera. Agric. For. Meteorol., 184: 117-136.

Cour, P., 1974. Nouvelles technique de détection des flux et des retombées polliniques: étude de la sedimentation des pollens et des spores à la surface du sol. Pollen et Spores XVI (1 ): 103-141.

Cour, P. and Van Camp, M., 1980. Prèvisions de récoltes á partir du contenu pollinique de l'atmosphere. C.R. Acad. Sci. Paris (290): 1043-1046.

Cunha, M. et al., 2003a. Early estimate of wine production using airborne pollen samples: application to northern Portugal. Polen, 13: 325-331.

Cunha, M., Abreu, I., Pinto, P. and Castro, R., 2003b. Airborne Pollen Samples for Early-Season Estimates of Wine Production in a Mediterranean Climate of Northern Portugal. American Journal of Enology and Viticulture 54 (3 ): 189-194.

Cunha, M., Costa, P., Abreu, I., Pinto, P. and Castro, R., 1999. Early estimate of wine prodction by means of airborne pollen: Demarcated Region of Douro. Ciência e Técnica Vitivinicola, 14(2): 45-54.

Cunha, M., Marcal, A.R.S. and Silva, L., 2010. Very early prediction of wine yield based on satellite data from VEGETATION. International Journal of Remote Sensing, 31(12): 3125-3142.

Cunha, M., Ribeiro, H., Costa, P. and Abreu, I., 2015. A comparative study of vineyard phenology and pollen metrics extracted from airborne pollen time series. Aerobiologia, 31(1): 45-56.

Cunha, M. and Richter, C., 2012. Measuring the Impact of Temperature Changes on the Wine Production in the Douro Region using the Short Time Fourier Transform International Journal of Biometeorology 56(2): 357-370.

CVRA, 2015. Comissão Vitivinícola Regional Alentejana, dados estatísticos sobre a produção de vinho no Alentejo, Available online at http://www.vinhosdoalentejo.pt (assessed 5 January 2015).

de la Fuente, M., Linares, R., Baeza, P., Miranda, C. and Lissarrague, J.R., 2015. Comparison of different methods of grapevine yield prediction in the time window between fruitset and veraison. J. Int. Sci. Vigne Vin., 49(1): 27-35.

Dunn, G., 2010. Yield Forecasting, Grape and wine research and development corporation.

Ebadi, A., May, P., Sedgley, M. and Coombe, B.G., 1995. Effect of low temperature near flowering time on ovule development and pollen tube growth in the grapevine (Vitis vinifera L.), cvs Chardonnay and Shiraz. . Australian Journal of Grape and Wine Research, 1(0): 11-18.

European Commission, 1997. Oliwin Project: agrometeorogical models for the estimation at harvest of olive and vine yield; regional and national level.

Fernandez-Gonzalez, M., Escuredo, O., Rodriguez-Rajo, F.J., Aira, M.J. and Jato, V., 2011a. Prediction of grape production by grapevine cultivar Godello in north-west Spain. J. Agric. Sci., 149: 725-736.

Fernandez-Gonzalez, M., Javier Rodriguez-Rajo, F., Jato, V., Escuredo, O. and Jesus Aira, M., 2011b. Estimation of yield 'Loureira' variety with an aerobiological and phenological model. Grana, 50(1): 63-72.

Finger, R., 2010. Revisiting the evaluation of robust regression techniques for crop yield data detrending. American Journal of Agricultural Economics, 92(1): 205-211. 
Fraga, H., Malheiro, A.C., Moutinho-Pereira, J. and Santos, J.A., 2014. Climate factors driving wine production in the Portuguese Minho region. Agric. For. Meteorol., 185(0): 26-36.

García-Mozo, H., Yaezel, L., Oteros, J. and Galán, C., 2014. Statistical approach to the analysis of olive long-term pollen season trends in southern Spain. Science of The Total Environment, 473-474: 103-109.

Guilpart, N., Metay, A. and Gary, C., 2014. Grapevine bud fertility and number of berries per bunch are determined by water and nitrogen stress around flowering in the previous year. European Journal of Agronomy, 54(0): 9-20.

Gujarati, D., 1995. Basic econometrics. McGraw-Hill, Inc., United Sates, New York.

Huglin, P. and Schneider, C., 1998. Research de méthodes de prévision quantitative de la vendage. Bulletin de I'Organisation Internationale de la Vigne et du Vin, 58: 71-89.

Hyndman, R.J. and Koehler, A.B., 2006. Another look at measures of forecast accuracy. International Journal of Forecasting, 22(4): 679-688.

Jones, G.V., 2007. Climate Changes and the global wine industry, 13th Australian wine industry technical Conference, Adelaide, Australia.

Jones, G.V. and Davis, R.E., 2000. Climate influences on grapevine phenology, grape composition, and wine production and quality for Bordeaux, France. American Journal of Enology and Viticulture, 51(3): 249-261.

Kennelly, M.M., Gadoury, D.M., Wilcox, W.F., Magarey, P.A. and Seem, R.C., 2005. Seasonal development of ontogenic resistance to downy mildew in grape berries and rachises. Phytopathology, 95(12): 1445-1452.

Lagerstrom, R. et al., 2015. Pollen Image Classification Using the Classifynder System: Algorithm Comparison and a Case Study on New Zealand Honey. In: C. Sun, T. Bednarz, T.D. Pham, P. Vallotton and D. Wang (Editors), Signal and Image Analysis for Biomedical and Life Sciences. Advances in Experimental Medicine and Biology. SpringerVerlag Berlin, Berlin, pp. 207-226.

Legates, D.R. and McCabe, G.J., 1999. Evaluating the use of "goodness-of-fit" Measures in hydrologic and hydroclimatic model validation. Water Resources Research, 35(1): 233-241.

Lltejos, R., Bartroli, R., Esteban, A. and Riera, S., 1993. Forecasting hazelnut (Corylus avellana L.). Crop production based on monitoring airborne pollen concentration., International symposium on fruit, nut and vegetable production engineering., Sapian, Valencia, pp. 18-25.

Lobell, D., Cahill, K. and Field, C., 2007. Historical effects of temperature and precipitation on California crop yields. Climatic Change, 81(2): 187-203.

May, P., 2004. Flowering and Fruitset in Grapevines. Lythrum Press, Australia.

Montgomery, D., Peck, E. and Geoffrey, V., 2012. Introduction to linear regression analysis. Viley, Adelaid, Australia, 672 pp.

Moriasi, D.N. et al., 2007. Model evaluation guidelines for systematic quantification of accuracy in watershed simulations. Transactions of the ASABE, 50(3): 885-900.

Nash, J.E. and Sutcliffe, J.V., 1970. River flow forecasting through conceptual models part I - A discussion of principles. Journal of Hydrology, 10(3): 282-290.

Nuske, S. et al., 2014. Automated Visual Yield Estimation in Vineyards. Journal of Field Robotics, 31(5): 837-860.

OIV, 2015. Organisation Internationale de la Vigne et du Vin - Statistiques, Available online at http://www.oiv.int (assessed 15 January 2015).

Ortega, A., Martí, C., Mora, S. and Ruiz, V., 1998. Statistic considerations relating to forecast of wine production by airborne pollen concentration. Viticultura/Enologia Profissional, 55: 5-18.

Oteros, J. et al., 2014. Better prediction of Mediterranean olive production using pollen-based models. Agronomy for Sustainable Development, 34(3): 685-694.

Palm, R. and Dagnelie, P., 1993. Tendance général et effects du climat dans la prévision des rendements agricoles des diferents pays de la C.E. .

Panigai, M. and Moncomble, D., 1988. La prévision de récoltes en Champagne. Le vigneron Champanois, 6: 359-367.

Pearson, R. and Goheen, A., 1990. Compendium of grape diseases. American Phytopathological Society, Unitaded Sates, Minessota, $380 \mathrm{pp}$.

Pereira, L.S., Paredes, P., Rodrigues, G.C. and Neves, M., 2015. Modeling malt barley water use and evapotranspiration partitioning in two contrasting rainfall years. Assessing AquaCrop and SIMDualKc models. Agricultural Water Management, 159(Complete): 239-254. 
Perry, J., Debuisson, S. and Moncomble, D., 2015. Outils de prédiction du rendement en Champagne. Les capteurs à pollens. Le vigneron Champanois, 6: 32-37.

Picard, R. and Cook, D., 1984. Cross-validation of regression models. Journal of American Statistic Association, 79: 575583.

Pinchon, O., 1983. Contribuition a l'étude du pollen et de la polinisation du pommier (Mallus pimula Miller) et previsions de recolte à partir de l' analyse du contenu pollinique de l' atmosphere. , Ecole National Superior Agronomie de Montpellier, France.

Qian, B.D., De Jong, R., Warren, R., Chipanshi, A. and Hill, H., 2009. Statistical spring wheat yield forecasting for the Canadian prairie provinces. Agric. For. Meteorol., 149(6-7): 1022-1031.

Quiroga, S. and Iglesias, A., 2009. A comparison of the climate risks of cereal, citrus, grapevine and olive production in Spain. Agricultural Systems, 101(1-2): 91-100.

Reidsma, P., Ewert, F., Lansink, A.O. and Leemans, R., 2010. Adaptation to climate change and climate variability in European agriculture: The importance of farm level responses. European Journal of Agronomy, 32(1): 91-102.

Reis, R. and Lamelas, H., 1988. Statistical study of decade series of water balance and its components of potencial evapotranspiration calculated by Penman's method. Vol. 36, Instituto Nacional de Meteorologia e Geofisica, Lisbon.

Ribeiro, H., Cunha, M. and Abreu, I., 2007a. Definition of the main pollen season using a logistic model. Annals of Agricultural and Environmental Medicine, 14(2).

Ribeiro, H., Cunha, M. and Abreu, I., 2007b. Improving early-season estimates of olive production using airborne pollen multi-sampling sites. Aerobiologia, 23(1): 71-78.

Ribeiro, H., Cunha, M. and Abreu, I., 2009. A bioclimatic model for forecasting olive yield. J. Agric. Sci., 147: 647-656.

Rittenour, W.R., Hamilton, R.G., Beezhold, D.H. and Green, B.J., 2012. Immunologic, spectrophotometric and nucleic acid based methods for the detection and quantification of airborne pollen. Journal of Immunological Methods, 383(1-2): 47-53.

Rojo, J., Rapp, A., Lara, B., Fernández-González, F. and Pérez-Badia, R., 2015. Effect of land uses and wind direction on the contribution of local sources to airborne pollen. Science of The Total Environment, 538: 672-682.

Sabbatini, P. and Howell, G.S., 2012. Predicting harvest yield in juice and wine and wine grape vineyards.

Santos, J.A., Grätsch, S.D., Karremann, M.K., Jones, G.V. and Pinto, J.G., 2013. Ensemble projections for wine production in the Douro Valley of Portugal. Climatic Change, 117(1-2): 211-225.

Scheifinger, H. et al., 2013. Monitoring, Modelling and Forecasting of the Pollen Season. In: M. Sofiev and K.-C. Bergmann (Editors), Allergenic Pollen. Springer Netherlands, pp. 71-126.

Tedeschi, L.O., 2006. Assessment of the adequacy of mathematical models. Agricultural Systems, 89(2-3): 225-247.

Thornthwaite, C.W., 1948. An approach toward a rational classification of climat. Geografical Review, 38(1): 55-94.

Urhausen, S., Brienen, S., Kapala, A. and Simmer, C., 2011. Climatic conditions and their impact on viticulture in the Upper Moselle region. Climatic Change, 109(3-4): 349-373.

Valdes-Gomez, H. et al., 2009. Modelling soil water content and grapevine growth and development with the STICS crop-soil model under two different water management strategies. J. Int. Sci. Vigne Vin., 43(1): 13-28.

Vasconcelos, M.C., Greven, M., Winefield, C.S., Trought, M.C.T. and Raw, V., 2009. The Flowering Process of Vitis vinifera: A Review. American Journal of Enology and Viticulture, 60(4): 411-434.

Vossen, P. and Rijks, D., 1995. Early crop yield assessment of the EU countries: The system implemented by the Join Research Centre.

Ye, T., Nie, J., Wang, J., Shi, P. and Wang, Z., 2015. Performance of detrending models of crop yield risk assessment: evaluation on real and hypothetical yield data. Stoch Environ Res Risk Assess, 29(1): 109-117. 


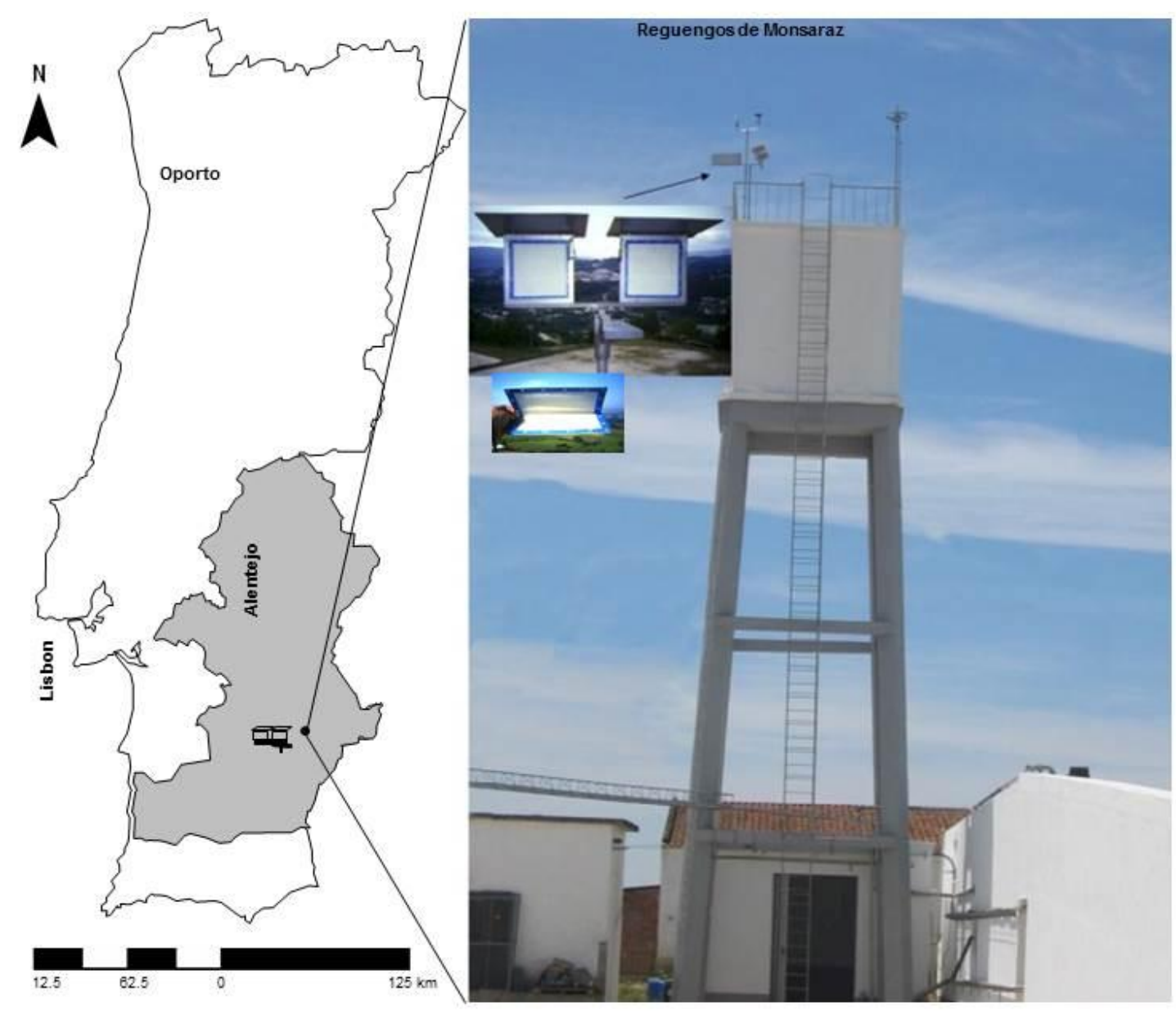

Fig.1 


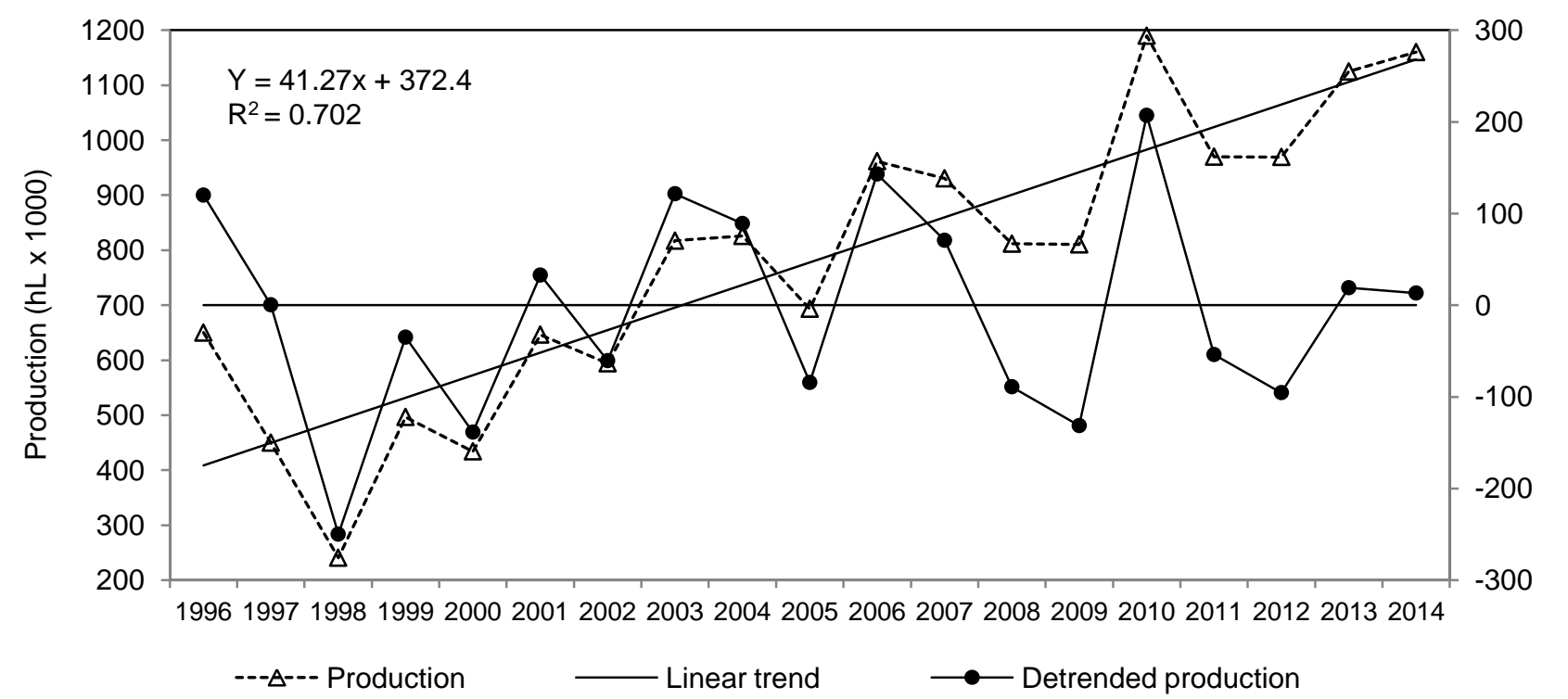

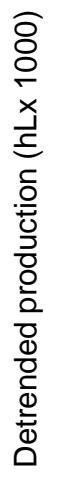

Fig. 2 


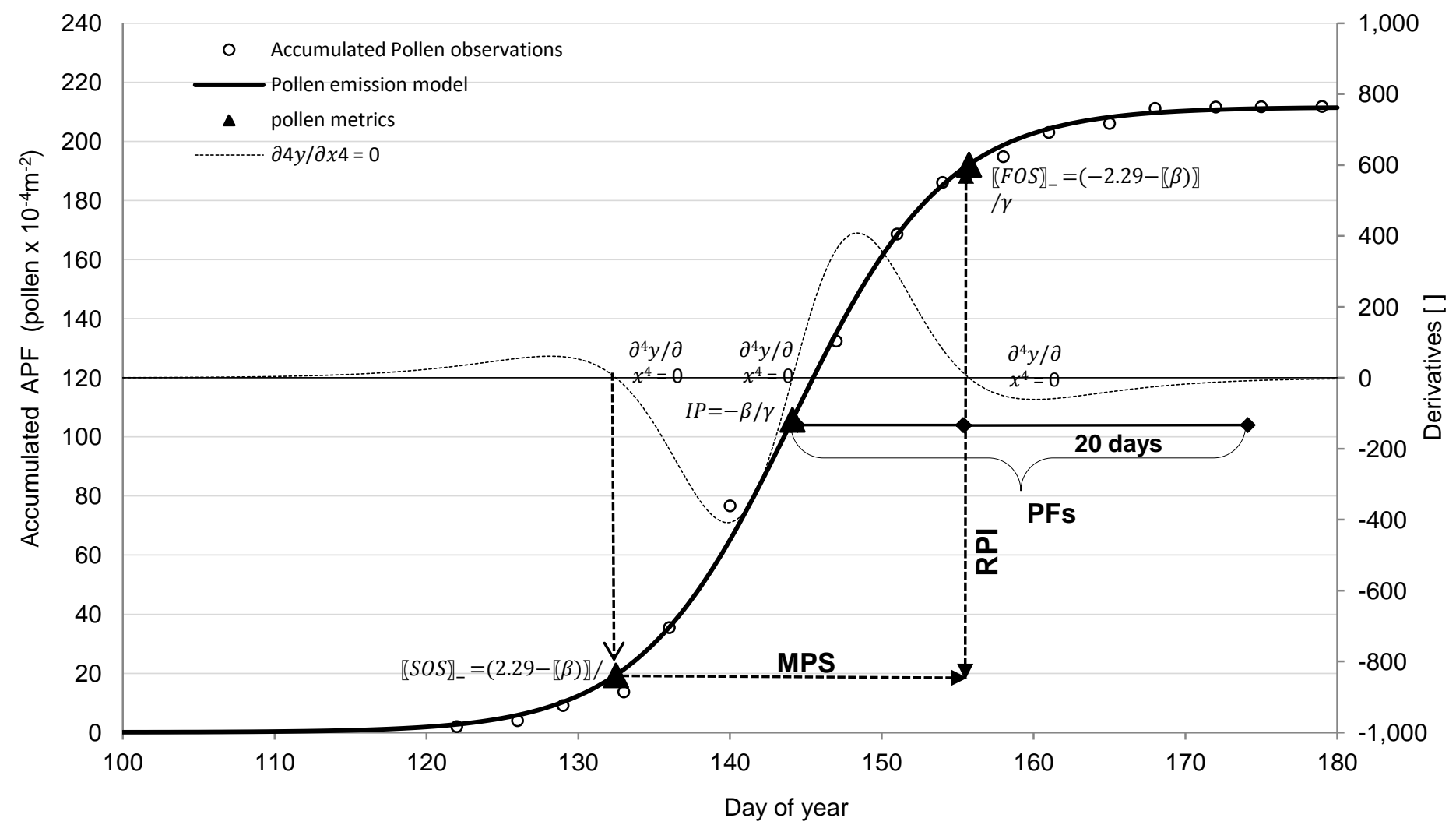

Fig. 3 


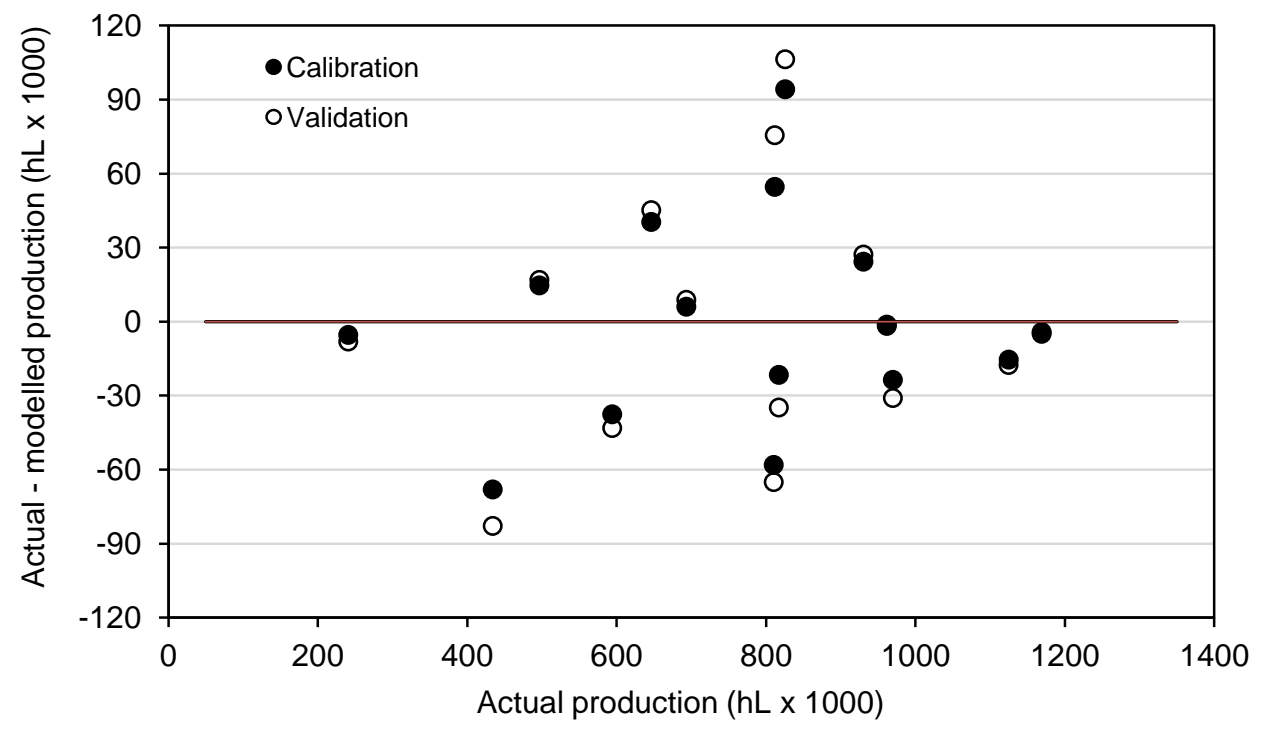

Fig. 4 


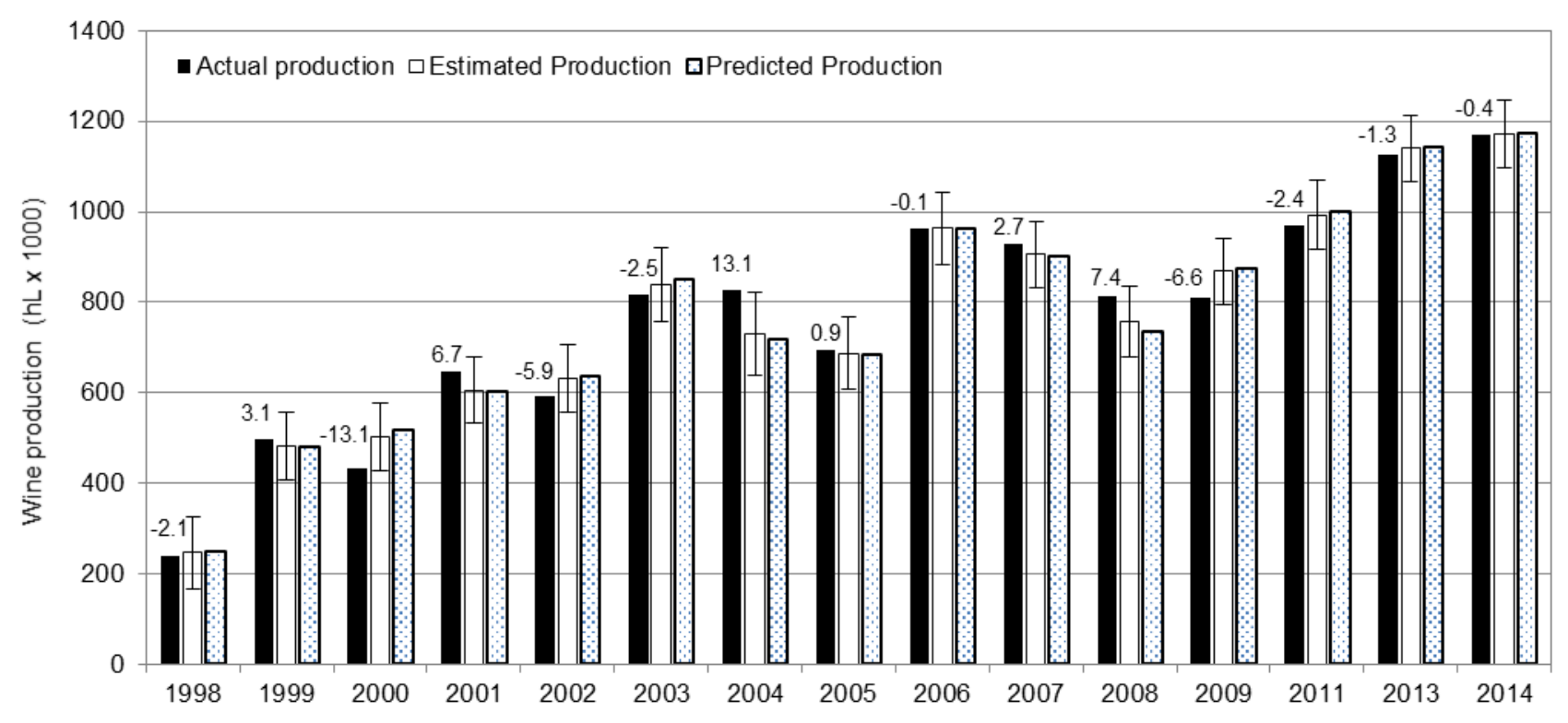

Fig. 5 
Table 1 - Descriptive statistics for the derived pollen emission metrics, meteorological data during the grapevine cycle, and variables of the forecast model from 1998 to 2014 in Alentejo.

\begin{tabular}{|c|c|c|c|c|c|}
\hline Variable & unit & Maximum & Minimum & Average & $\mathrm{cv}(\%)$ \\
\hline \multicolumn{6}{|l|}{ Model's variables } \\
\hline Wine Production (PRD) & hL x 1000 & 1164 & 241 & 764 & 33 \\
\hline Regional Pollen Index (RPI) & Pollen $\times 10^{-4} \mathrm{~m}^{2}$ & 1064 & 124 & 475 & 61 \\
\hline Fruit-set classification $(\mathrm{Fs})$ & classification & $1(60 \%)$ & $-1(14 \%)$ & 0.47 & 159 \\
\hline \multicolumn{6}{|l|}{ Pollen emission model (PEM) } \\
\hline Start of Season (SOS) & DOY & 137.7 & 118.2 & 129.2 & 4.9 \\
\hline Final of Season (FOS) & DOY & 154.8 & 139.5 & 145.7 & 3.4 \\
\hline $\begin{array}{l}\text { Mean derived flowering date } \\
\text { (IP or DF) }\end{array}$ & DOY & 146.3 & 131.7 & 137.4 & 3.7 \\
\hline Main Pollen Season (MPS) & Days & 28.3 & 7.7 & 16.5 & 31.8 \\
\hline Filters exposed & Observation & 15 & 10 & 11.7 & 20.4 \\
\hline \multicolumn{6}{|c|}{ Meteorological conditions during budburst to flowering (DF) } \\
\hline Mean temperature $(\mathrm{Tm})$ & ${ }^{\circ} \mathrm{C}$ & 14.9 & 12.6 & 13.2 & 5.1 \\
\hline Precipitation $(\mathrm{R})$ & $\mathrm{mm}$ & 257.5 & 33.4 & 92.6 & 83.2 \\
\hline \multicolumn{6}{|c|}{ Meteorological conditions during flowering to fruit-set period (PFs) } \\
\hline Mean temperature (Tm) & ${ }^{\circ} \mathrm{C}$ & 23.5 & 17.9 & 21.4 & 9.8 \\
\hline $\begin{array}{l}\text { Days with temp. }<15^{\circ} \mathrm{C} \\
(\mathrm{nTm}<15)\end{array}$ & Days & 3.0 & 0.0 & 0.4 & 264.7 \\
\hline $\mathrm{nTm}<15^{*}$ & Days & 3.0 & 0.0 & 0.4 & 265.4 \\
\hline Number of rainy days (nR) & Days & 13.0 & 0.0 & 4.5 & 114.3 \\
\hline $\mathrm{nR} *$ & Days & 8.0 & 0.0 & 2.8 & 97.9 \\
\hline$\%$ nR & $\%$ & 46.4 & 0.0 & 15.9 & 110.1 \\
\hline \multicolumn{6}{|c|}{ Meteorological conditions during flowering to harvest period } \\
\hline Harvest $(\mathrm{H})$ & DOY & 244.0 & 232.0 & 236.5 & 1.8 \\
\hline IF - Harvest & Days & 111.0 & 93.0 & 97.2 & 6.5 \\
\hline Mean temperature (Tm) & ${ }^{\circ} \mathrm{C}$ & 23.7 & 21.7 & 21.7 & 3.1 \\
\hline Precipitation (R) & $\mathrm{Mm}$ & 151.5 & 3.2 & 37.7 & 131.2 \\
\hline Number of rainy days (nR) & Days & 20.0 & 4.0 & 11.1 & 45.1 \\
\hline \multicolumn{6}{|c|}{ Meteorological conditions during January to December } \\
\hline Mean temperature $(\mathrm{Tm})$ & ${ }^{\circ} \mathrm{C}$ & 45.3 & 15.8 & 19.1 & 53.7 \\
\hline Precipitation $(\mathrm{R})$ & $\mathrm{Mm}$ & 628.4 & 372.2 & 504.2 & 24.8 \\
\hline
\end{tabular}


Table 2. The assumptions diagnostic and goodness-of-fit indicators relative to the model calibration and the model validation for the sampling period $(n=15)$.

\begin{tabular}{lcc}
\multicolumn{1}{c}{ Statistics } & Model Calibration & Model Validation (LOO) \\
\hline Diagnostic of model assumptions & & \\
Leverage test [ ] & $<0.314$ & $<.323$ \\
Jarque-Bera test (p) & 0.630 & 0.459 \\
Breusch-Pagan test (p) & 0.709 & 0.570 \\
Goodness-of-fit: association measures & & \\
$\mathrm{R}^{2} / \mathrm{R}^{2}$ Loo [ ] & $0.863(\mathrm{p}<0.000)$ & $0.811(\mathrm{p}<0.000)$ \\
$\mathrm{R}^{2}(1: 1)$ [ ] & 0.836 & 0.790 \\
$\mathrm{~b}(1: 1)[$ ] & 0.999 & 0.946 \\
NSE [ ] & 0.832 & 0.782 \\
Goodness of fit: residual indices & & \\
AAE $\left(10^{-3} \mathrm{hL}\right)$ & 31.3 & 37.9 \\
RMSE $\left(10^{-3} \mathrm{hL}\right)$ & 40.9 & 48.8 \\
ARE $(\%)$ & 4.6 & 5.6 \\
PBias $(\%)$ & 0.000 & -0.071 \\
\hline
\end{tabular}

Leverage statistic test. Jarque-Bera test (p) and Breusch-Pagan test (p): probability value for the diagnostic test to the normality and homoscedasticity of the residuals respectively. LOO: Leave-one-out cross validation; $\mathrm{R}^{2}{ }_{\text {LOO }}$ determination coefficient for the cross validation. $\mathbf{R}^{2}(\mathbf{1 : 1})$ and $\mathbf{b}(\mathbf{1 : 1})$ : are, respectively the determination coefficient and regression coefficient through the origin. NSE: model efficiency test. AAE: average absolute error, RMSE: root mean square error, ARE: average relative error and PBias: percent of bias. 
Graphical Abstract

Pollen-based predictive modelling of wine

2. Pollen Filtring

production: application to an arid region

\section{Pollen emission}
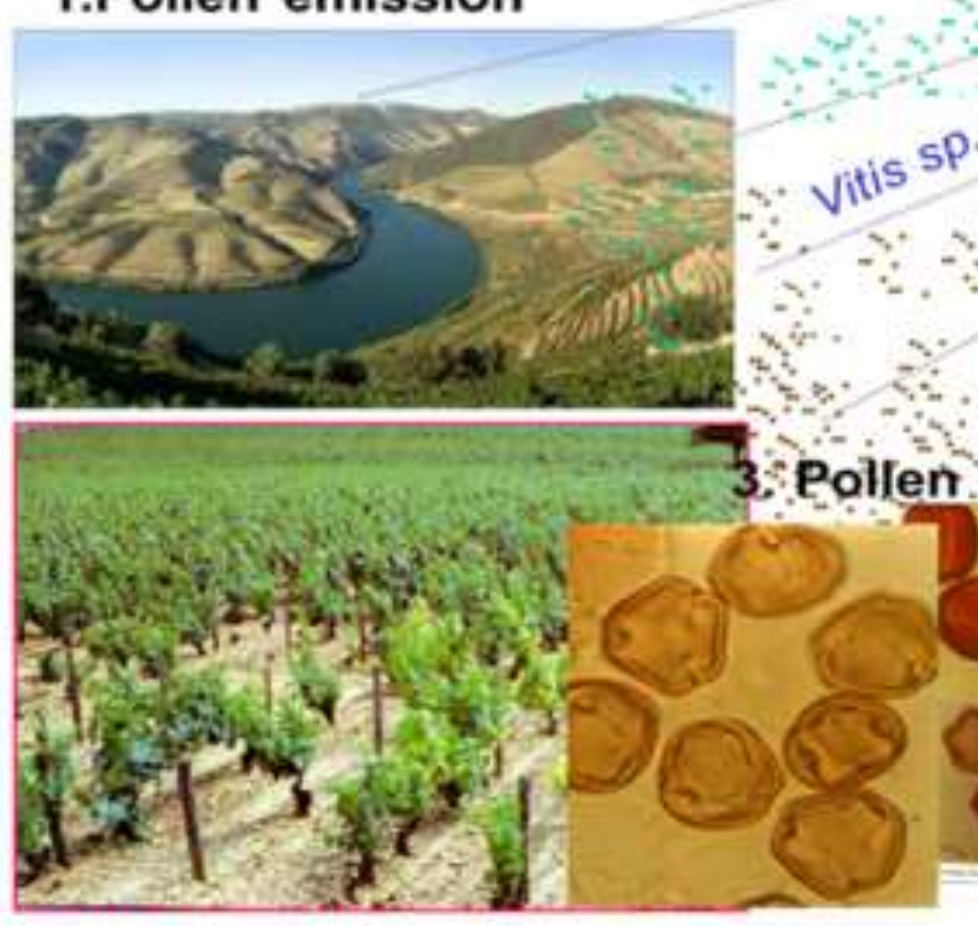

3. Poilen counts

F2. How accurate can they get?

\begin{tabular}{|c|c|c|}
\hline \multicolumn{2}{|c|}{ Yield variation explanation } & Pollen-based Model \\
\hline Bunches/ & $60 \%$ & Pollen $(R P I) \Rightarrow 71 \%$ \\
\hline Berries per vine & $30 \%$ & Fruit-set $(F s)=>15 \%$ \\
\hline Weight per berry & 10:5? & \\
\hline
\end{tabular}

European Joumal of Agronomy

Mảrio Cunha': Helena Ribeiro and IIda Abreu movetuemaicicar apot

F1. Regional Pollen Index (RPI)

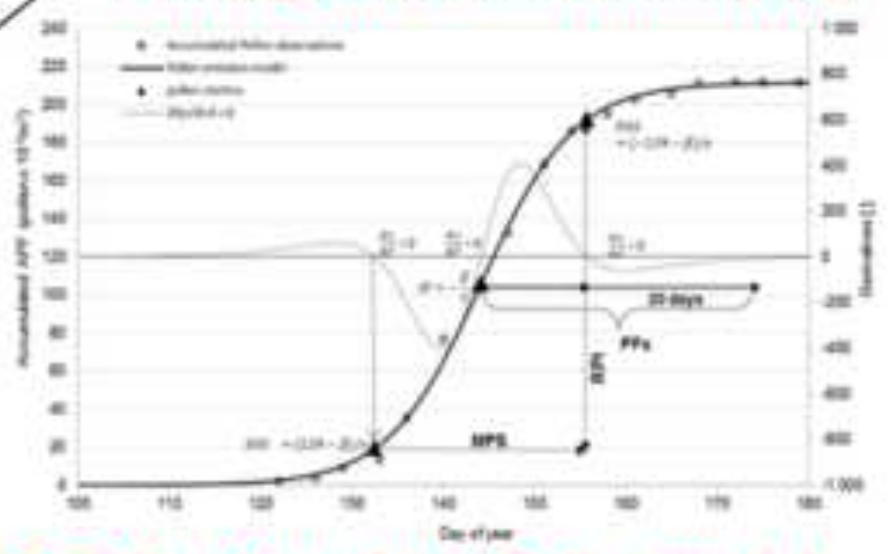

F3. Pollen-based predictive model

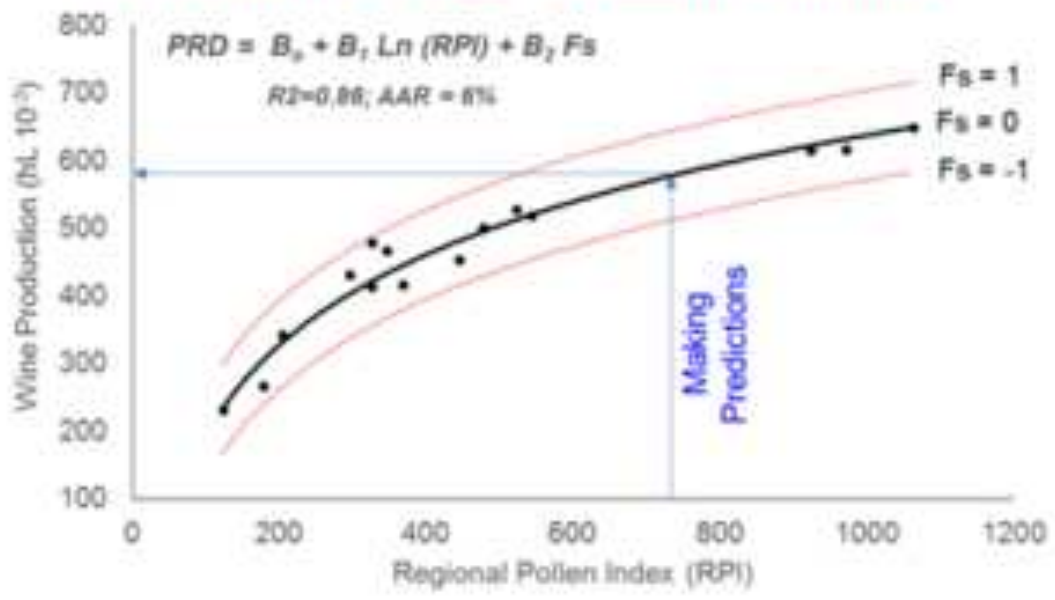

